PROFETIKA, Jurnal Studi Islam, Vol. 19, No.1 Juni 2018: 6 - 12

\title{
IMPLEMENTASI PENDIDIKAN AGAMA ISLAM BERBASIS MASYARAKAT DI TEMANGGUNG
}

\author{
Abdul Malik \\ Sekolah Tinggi Ilmu Tarbiyah Muhammadiyah Tegal \\ E-Mail: a.malik122@yahoo.co.id
}

Sabar Narimo

Universitas Muhammadiyah Surakarta

E-Mail: sn124@ums.ac.id

\begin{abstract}
Community Based Education is an educational model of society, by society, and for society that is education intended, implemented, developed and developed by the community. This research is intended to apply community-based Islamic religious education, supported factors and supporting factors and inhibiting the implementation of Islamic religious education that is community based in SMP Negeri 2 Candiroto and SMP Muhammadiyah 5 Kandangan presented in descriptive qualitative. The results of the analysis of the implementation of community-based religious education in SMP Negeri 2 Candiroto and SMP Muhammadiyah 5 Kandangan in the planning, implementation, and evaluation of education is still dominated by the role of teachers and principals as Top Managers. Community involvement in educational planning is by providing input and suggestions of education implementation that emphasizes on the mastery of reading and writing al-Quran and prayer. In the implementation of society involved in certain events in learning and religious activities. And in the evaluation of education, conducted by teachers and principals who reported the implementation to the community. Impacts that arise in the implementation of community-based Islamic education in SMP Negeri 2 Candiroto and SMP Muhammadiyah 5 Kandangan Temanggung district intertwined symbiosis mutualism between schools with the community, and on the other the budget of education costs increased. Supporting factors: the culture of gotong-royong that is still strongly rooted in the community. Factors inhibiting Human Resources (HR) and the availability of funds for education.
\end{abstract}

Keywords: Islamic Religious Education; Community Based Education; the role of society.

Abstrak: Pendidikan Berbasis Masyarakat merupakan model pendidikan dari masyarakat, oleh masyarakat, dan untuk masyarakat yaitu pendidikan yang direncanakan, dilaksanakan, dinilai dan dikembangkan oleh masyarakat.

Penelitian ini bermaksud menganalisis bagaimanakah implementasi pendidikan

agama Islam berbasis masyarakat, dampak-dampak yang ditimbulkan serta faktor-faktor pendukung dan penghambat implementasi pendidikan pendidikan agama Islam berbasis masyarakat di SMP Negeri 2 Candiroto dan SMP Muhammadiyah

5 Kandangan yang disajikan secara deskriptifkualitatif. Hasil analisis implementasi pendidikan agama Islam berbasis masyarakat di SMP Negeri 2 Candiroto dan SMP Muhammadiyah 5 Kandangan dalam perencanaan, pelaksanaan, dan evaluasi pendidikan masih di dominasi oleh peran guru dan kepala kepala sekolah sebagai Top Manager. Keterlibatan masyarakat dalam perencanaan pendidikan yaitu dengan memberikan masukan dan saran pelaksanaan pendidikan yang menekankan pada penguasaan baca-tulis al Quran dan shalat. Dalam pelaksanaan masyarakat terlibat pada event-event tertentu dalam pembelajaran maupun kegiatan bersifat keagamaan. Dan dalam evaluasi pendidikan, dilakukan oleh guru maupun kepala sekolah 
yang melaporkan pelaksanaan kepada masyarakat. Dampak yang muncul dalam implementasi pendidikan agama Islam berbasis masyarakat di SMP Negeri 2 Candiroto dan SMP Muhammadiyah 5 Kandangan kabupaten Temanggung terjalin simbiosis mutualisme antara sekolah dengan masyarakat, dan disisi lain anggaran biaya pendidikan semakin besar. Faktor pendukung: kultur gotong-royong yang masih kuat mengakar dimasyarakat. Faktor penghambat Sumber Daya Manusia (SDM) dan ketersediaan dana untuk pendidikan.

Kata kunci: Pendidikan Agama Islam; Pendidikan Berbasis Masyarakat; peranmasyarakat.

\section{PENDAHULUAN}

Dengan diberlakukannya otonomi pendidikan, berimplikasi kepada perubahan sistem manajemen pendidikan dari pola sentralisasi ke desentralisasi. Pendidikan berbasis masyarakat dan Manajemen Berbasis Sekolah adalah wujud nyata demokratisasi dan desentralisasi pendidikan.1 Pendidikan Berbasis Masyarakat dalam perspektif historis merupakan pengembangan dari pendidikan berbasis sekolah dengan penekanan pada partisipasi masyarakat dalam pendidikan. Jadi pendidikan berbasis masyarakat merupakan model pendidikan memberikan otonomi sekolah, warga sekolah dan masyarakat untuk terlibat secara langsung dalam penyelenggaraan dan meningkatkan mutu pendidikan.2

Pendidikan berbasis masyarakat merupakan Pendidikan yang dirancang, dilaksanakan, dinilai dan dikembangkan oleh masyarakat yang mengarah pada usaha menjawab tantangan dan peluang yang ada di lingkungan masyarakat tertentu dengan berorientasi pada masa depan.3

Menurut Hamilton dan Cunningham tentang pendidikan berbasis masyarakat: "Community-based education operates on the assumption that a given community, whether urban or rural, has the potential to solve many of its own problems by relying on its own resources and by mobilizing community action for problem resolution."4 Yang menjelaskan bahwa Pendidikan berbasis masyarakat beroperasi.

Dengan asumsi bahwa suatu masyarakat, baik perkotaan maupun pedesaan, memiliki potensi untuk memecahkan masalahnya sendiri dengan mengandalkan sumber dayanya sendiri dan dengan memberdayakan tindakan masyarakat untuk penyelesaian masalah. Jadi, sebuah pendidikan dianggap berbasis masyarakat jika semua yang terkait di dalamnya berada ditangan atau dikelola oleh masyarakat, seperti perencanaan, pelaksanaan dan evaluasinya. Sebaliknya, jika semua penyelenggaraan

1 HR Tilaar, Paradigma Baru Pendidikan Nasional, (Jakarta: Rineka Cipta, 2000), hlm 105

2 Umaedi, Managemen Peningkatan Mutu Berbasis Sekolah, (Jakarta: Departemen Pendidikan Nasional Direktorat Jendral Pendidikan Dasar dan Menengah Direktorat Sekolah Lanjutan Tingkat Pertama, 2001), hlm. 3

3 Fasli Jalal dan Dedi Supriadi, Reformasi Pendidikan Dalam Konteks Otonomi Daerah,

(Yogyakarta: Adicita Karya Nusa, 2001), hlm. 186.

4 Hamilton E. Cunningham P. (1989). Community-based adult education. In

MerriamS.CunninghamP. (Eds.), Handbook of adult and continuing education (pp. 439-450). San

Francisco, CA: Jossey-Bass. pendidikan ditentukan pemerintah maka disebut pendidikan berbasis pemerintah atau negara (statebased education) atau jika semuanya ditentukan oleh sekolah maka disebut pendidikan berbasis sekolah (school-based education). 5

Toto Suharto membagi konsep pendidikan berbasis masyarakat menjadi 2 kategori yaitu organik dan tradisional.6 Pendidikan berbasis masyarakat organik yaitu lembaga pendidikan yang kebijakankebijakan kependidikannya secara mandiri dan otonom, serta pendanaan pendidikan yang berbasis swadana dan swadaya masyarakat tanpa ada campur tangan pemerintah. Sebaliknya pendidikan berbasis masyarakat tradisional, lembaga pendidikan yang kebijakan-kebijakan pendidikannya, baik sebagian ataupun keseluruhan, merupakan adopsi dan adaptasi dari kebijakan pendidikan pemerintah.

Konsep pendidikan berbasis masyarakat telah lama dikenal di Indonesia bahkan telah ada sebelum periode kemerdekaan. Pendidikan yang berkembang pada saat itu berbentuk pesantren. Lembaga pendidikan Islam yang dikelola oleh para ulama sebagai bentuk perlawanan masyarakat terhadap pendidikan yang diterapkan oleh pemerintah kolonial belanda yang mencengkeram indonesia selama lebih dari tiga ratus tahun. Bahkan Azyumardi Azra, secara khusus pernah menyampaikan bahwa partisipasi masyarakat muslim di Indonesia dalam rangka pendidikan berbasis masyarakat telah dilaksanakan lebih lama lagi yaitu setua sejarah perkembangan Islam di nusantara ini.7 Perkembangan sekolah Islam di Asia Tenggara terutama di Indonesia semakin pesat disebabkan oleh pengaruh fenomena revivalis Islam di seluruh dunia, khususnya Konferensi Pendidikan Muslim Internasional yang pertama kali diadakan di Makkah 1977, Kedua di Islamabad 1980, Ketiga di Dakka (Bangladesh), 1981, Keempat di Jakarta 1982, Kelima di Kairo 1987 dan Keenam di Makkah 1993 dan Ketujuh di Afrika Selatan 1996. Konferensi ini telah membahas pendidikan agama ini dari tingkat dasar sampai tingkat menengah dan menghasilkan panduan untuk pelaksanaannya. 8

5 Zubaedi, Pendidikan Berbasis Masyarakat..., hlm. 134

6 Toto Suharto, Pendidikan Berbasis Masyarakat...,hlm. 144

7 Azyumardi Azra, Masalah dan Kebijakan Pendidikan Islam di Era Otonomi Daerah, Makalah disampaikan pada Konferensi Nasional Manajemen Pendidikan di Hotel Indonesia, Jakarta 8-10 Agustus 2002, kerjasama Universitas Negeri Jakarta dengan Himpunan Sarjana Administrasi Pendidikan Indonesia, hlm. 5-6

8 Che Noraini Hashim dan Hasan Langgulung, Islamic

Religious Curriculum in Muslim Countries: The Experiences of Indonesia and Malaysia, Bulletin of Education \& Research, June 
Dalam pendidikan yang berhubungan dengan ajaran Islam terdapat dua istilah yang selama ini dianggap sama, padahal memiliki subtansi yang berbeda yaitu "pendidikan agama Islam" dan "Pendidikan Islam" meskipun maksud dan tujuan kedua istilah tersebut mengarah pada satu makna, yaitu pendidikan yang berlandaskan pada ajaranajaran Islam. Pendidikan agama Islam telah dibakukan sebagai nama mata pelajaran yang seharusnya dinamakan "Agama Islam", karena yang di ajarkan adalah agama Islam. Kata "pendidikan" ini mengikuti nama setiap mata pelajaran. Dalam hal ini pendidikan agama Islam sejajar dengan pendidikan Matematika, dengan nama mata pelajarannya adalah Matematika, atau pendidikan lainya. Pendidikan Islam merupakan nama sistem, yaitu sistem pendidikan yang islami, yakni pendidikan yang dipahami dan dikembangkan serta disusun dari ajaran dan nilai-nilai fundamental yang terkandung dalam al-Quran dan Sunnah.9

Pendidikan agama Islam sebagai mata pelajaran saat ini tidak hanya didominasi oleh lembaga pendidikan Islam seperti rangkang, dayah, meunasah di Aceh, surau di Minangkabau, pesantren dan Madrasah, akan tetapi juga masuk pada lembaga pendidikan umum. Dalam kontek pendidikan umum yang berlaku di Indonesia merupakan hasil pemikiran Ki Hadjar Dewantara terdapat kesamaan dengan pendidikan Islam terutama pada prosesnya yaitu membimbing seseorang atau menuntun.10Perbedaannya pendidikan Ki Hadjar Dewantara berlandaskan kodrat pribadi seseorang dan pengaruh keadaan yang mengelilinginya sedangkan Pendidikan Islam berlandaskan ajaran Islam yaitu al Qur'an dan as Sunnah. Dalam UU Sisdiknas Nomor 20 Tahun 2003, khususnya Pasal 37 Ayat I huruf a disebutkan: Kurikulum pendidikan dasar dan menengah wajib memuat pendidikan agama.11

Dengan mewajibkan Pendidikan agama Islam dalam kurikulum dasar dan menengah diharapkan mampu memberikan solusi dalam memperbaiki akhlak/moral masyarakat yang sedang menghadapi tiga krisis global yaitu krisis ekonomi, politik dan sosial.12Implementasi pendidikan agama Islam berbasis masyarakat diakomodir melalui pasal 55 (1) UU Sisdiknas 20/2003 yang menyatakan bahwa masyarakat berhak menyelenggarakan pendidikan berbasis masyarakat pada pendidikan formal dan nonformal sesuai dengan kekhasan, lingkungan sosial, dan budaya dari oleh dan untuk kepentingan masyarakat. Dari pasal tersebut memberikan gambaran bahwa pendidikan berbasis masyarakat tidak dimonopoli oleh pendidikan nonformal. Padahal ensensi pendidikan berbasis masyarakat adalah

2008, Vol. 30, No. 1, pp. 1-19, hlm. 7

9 Wahyudi Noor, Jurnal Qathruna, Rekontruksi Pendidikan Agama Islam, (Banten:

penerbit, 2014). Vol. 1., hlm. 43

10 Muthoifin, Jurnal Studi Islam dan Sosial, Vol 2, No 1

Wahana Akademika page. 61 -

75, (Semarang: Kopertais Wilayah X Jawa Tengah, 2015)

11 Anwar Arifin, Memahami Paradigma Baru Pendidikan Nasional dalam Undang-

Undang Sisdiknas, (Jakarta : DepagRI, 2003), hlm. 17

12 Abdul Khobir, Pendidikan Agama Islam di Era Globalisasi, Forum Tarbiyah, vol. 7

No. 1 2009, hlm. 3 pendidikan non formal. Sehingga memunculkan pertanyaan

(1) Bagaimanakah implementasi pendidikan agama Islam berbasis masyarakat dilembaga pendidikan formal dengan standar pendidikan yang telah ditetapkan oleh pemerintah dalam UU sisdiknas antara lain jumlah jam pelajaran 2 jam/minggu serta mengakomodir kebutuhan dan peran serta masyarakat.

(2) Bagaimanakah dampak implementasi pendidikan agama Islam berbasis masyarakat, dan

(3) Apakah faktor pendukung dan penghambat implementasi pendidikan agama Islam berbasis masyarakat.

\section{METODOLOGI PENELITIAN}

Penelitian ini menggunakan penelitian kualitatif, prosedur penelitian yang menghasilkan data deskriptif berupa katat-kata, catatan-catatan, yang berhubungan dengan makna, nilai serta pengertian.13Berdasarkan tempat penelitian maka penelitian termasuk jenis penelitian lapangan (field research). Sumber data penelitian ini ada dua macam, yaitu data sumber data primer dan sumber data sekunder. Sumber data Primer menurut Mohamad Ali, merupakan sumber informasi yang langsung mempunyai wewenang dan bertanggung jawab terhadap pengumpulan data.14Para informan yang dimaksud adalah komite sekolah, kepala sekolah, guru, orang tua, dan masyarakat. Sumber data sekunder adalah data yang diperoleh lewat pihak lain, tidak langsung diperoleh oleh peneliti dari subjek penelitiannya.15Data sekunder penelitian ini adalah dokumen-dokumen yang berupa catatan, dan bahan lain yang relevan dengan penelitian ini. Hasil data yang telah terkumpul selanjutnya dianalisis untuk menarik simpulan dengan analisis data yaitu terdiri dari reduksi data, penyaringan data, penarikan kesimpulan. 16

\section{HASIL DAN PEMBAHASAN}

Analisis pendidikan berbasis masyarakat kedua lembaga pendidikan tersebut merupakan iniasitif masyarakat sekitar. Hal ini sesuai konsep pendidikan berbasis masyarakat yang dikemukakan oleh Zubaedi, yaitu adanya lembaga atau wadah yang statusnya jelas dimiliki, dipinjam, dikelola, dan dikembangkan oleh masyarakat. Latar belakang pendirian dari SMP Negeri 2 Candiroto merupakan inisiatif masyarakat terutama tokoh-tokoh masyarakat setempat yang merasa resah karena kurangnya sarana dan prasarana pendidikan didesa mereka sehingga 13 Kaelan, Metodelogi Penelitian Kualitatif Interdisipliner bidang sosial, budaya, filsafat, seni, agama dan humaniora, (Yogyakarta; Paradigma, 2012), Cet-1, hlm. 5

14 Mohamad Ali, Penelitian Kependidikan, Prosedur dan Strategi, (Bandung:Angkasa,

1999), hlm. 42

15 Saifuddin Azwar, Metode Penelitian, (Yogyakarta : Pustaka Pelajar, 2009), hlm. 91

16 B. Miles, dan A.M. Huberman, Analisa Data Kualitatif, terjemahan Tjetjep Rohendi

Rohidi, (Jakarta : Universitas Indonesia Press, 2002), hlm. 27. 
menyebabkan banyak anak di desa mereka yang hanya lulus SD dan membantu orang tua di ladang. Kemudian tokoh-tokoh masyarakat desa Canggal berinisiatif mengajukan bantuan pendirian sekolah kepada pemerintah kabupaten Temanggung dan akhirnya terealisasi pada tahun 2011, dengan status kepemilikan sekolah adalah Pemerintah Daerah Kabupaten Temanggung.

Hal serupa juga pada pendirian SMP Muhammadiyah 5 Kandangan berdiri berdasarkan keinginan dari beberapa tokoh Muhammadiyah yang berada di kecamatan Kandangan untuk mendirikan sekolah setingkat SMP selanjutnya pengelolaan pendidikan didukung kader-kader Muhammadiyah yang berprofesi sebagai guru. Jadi dalam Pengelolaan pendidikan berbasis masyarakat tidak bisa lepas dari kontribusi masyarakat baik secara individu sebagai tokoh masyarakat, tokoh agama maupun masyarakat yang peduli dengan pendidikan seperti perangkat desa, ustadz, kyai, atlit, pengusaha, guru, dan seniman, maupun kelompok masyarakat yang tergabung dalam suatu wadah atau organisasi kemasyarakatan seperti LSM, yayasan, pesantren dan paguyuban.

\section{IMPLEMENTASI PENDIDIKAN AGAMA ISLAM BERBASIS MASYARAKAT}

\section{Perencanaan dalam Implementasi Pendidikan Agama Islam Berbasis Masyarakat}

Partisipasi masyarakat dalam perencanaan pendidikan ketika menyusun rencana pembelajaran dengan melibatkan komite sekolah yang terdiri dari orang tua siswa, tokoh agama, dan tokoh masyarakat dengan para guru di SMP Negeri 2 Candiroto. Dalam rapat komite menghasilkan rumusan rencana pendidikan agama Islam secara umum berupa kegiatan keagamaan seperti pelaksanaan hari besar keagamaan yang melibatkan sekolah dengan masyarakat seperti kegiatan bulan Ramadhan, Isra' Mi'raj, Maulud nabi, perayaan iedul Fitri dan iedul Adha. Dalam hal teknis yang berkaitan dengan pendidikan agama Islam lebih menekankan pada kemampuan baca, tulis, hafalan al Quran dan praktek shalat dari rumpun mata pelajaran Pendidikan Agama Islam yang ada yaitu Al Quranhadits, Akidah, Akhlak, Fiqh dan Tarikh. Di SMP Muhammadiyah 5 Kandangan juga merencanakan pendidikan yang melibatkan anggota komite sekolah selain itu saran dan masukan dalam pelaksanaan pendidikan mendapat masukan dari unsur yayasan Muhammadiyah melalui pimpinan ranting Muhammadiya Malebo serta dari majelis Dikdasmen Muhammadiyah Kabupaten Temanggung. Kontribusi masyarakat dalam perencanaan pendidikan terutama dalam Pendidikan Agama Islam dengan penekanan pada praktek penyelenggara jenasah, baca tulis Al Quran dan Tahfidz tanpa mengkesampingkan rumpun mata pelajaran Pendidikan Agama Islam yang lainnya yang merupakan mata pelajaran ciri khusus lembaga pendidikan Muhammadiyah yaitu Al Quran-hadits, Akidah, Akhlak, Fiqh, Tarikh dan Kemuhammadiyahan.

Pada praktek perencanaan dalam implementasi pendidikan Agama Islam berbasis masyarakat yang ada di SMP Negeri 2 Candiroto dan SMP Muhammadiyah 5 Kandangan dilakukan bersamasama dengan antara pihak sekolah dengan masyarakat. Dengan kesepakatan perencanaan pendidikan agam Islam lebih menekankan pada rumpun Al Quranhadist dengan penguasaan membaca, menulis bahwa tahfidz Quran sebagai sumber utama ajaran Islam, rumpun Fiqh terutama dalam praktek ibadah seperti shalat wajib dan shalat sunnah, dan rumpun Akhlak dengan pembiasaan shalat berjamaah di masjid lingkungan sekolah.

\section{Pelaksanaan dalam Implementasi Pendidikan Agama Islam Berbasis Masyarakat}

Pelaksanaan pendidikan agama Islam di SMP Negeri 2 Candiroto masih didominasi oleh peran guru Pendidikan Agama Islam dengan dibantu guru yang lain dalam mengajar baca tulis al quran, dilakukan dengan tadarus bersama sebelum jam pelajaran dimulai. Peran masyarakat dengan membantu siswa belajar berdasarkan tugas rumah yang diberikan oleh guru kepada siswa dengan dibantu oleh guru mengaji dan tokoh agama yang berada dilingkungan masing-masing, seperti menghafal surat- surat pendek, membaca dan menulis surat Al Quran terkait tema mata pelajaran pendidikan agama Islam yang telah disampaikan di sekolah. Untuk keterlibatan masyarakat umum yang berkaitan kegiatan perayaan hari besar seperti menentukan tema, tokoh yang diundang, dan mengisi acara atau khotbah, sedangkan pada kegiatan pendidikan secara langsung belum dilakukan karena keterbatasan SDM masyarakat sekitar.

Di SMP Muhammadiyah 5 Kandangan dalam kegiatan pembelajaran Pendidikan Agama Islam juga masih di dominasi oleh para guru, karena pada dasarnya guru di SMP Muhammadiyah 5 kandangan adalah guru Pendidikan Agama Islam hal ini terbukti setiap hari kegiatan baca tulis dan tadarus al Quran dilakukan sebelum pelajaran dimulai yang dipimpin oleh guru yang mengisi mata pelajaran di jam pertama. Untuk mata pelajaran rumpun Pendidikan Agama Islam yang merupakan ciri khusus pendidikan muhammadiyah seperti Al Quran-hadits, Fiqh, Akidah- Akhlak, Tarikh, dan Kemuhammadiyahan tetap diampu oleh guru bidang studi masing-masing. Keterlibatan masyarakat dalam pendidikan dilakukan pada saat kegiatan-kegiatan tertentu sesuai dengan yang direncanakan oleh pihak sekolah dan komite sekolah. Partisipasi masyarakat maupun unsur yayasan dalam program pendidikan dengan mengisi kegiatan keagamaan seperti pada perayaan hari raya Isra'Miraj, Maulud Nabi, 
Perayaan Iedul Fitri dan Iedul Adha dan Nuzulul Quran sebagai sarana sosialisasi pihak sekolah kepada masyarakat. Kegiatan pendidikan lainnya dengan mengundang tokoh agama dalam mengisi kegiatan bulan ramadhan memberikan pelatihan dan motivasi tahfidz quran kepada siswa, dan pelatihan praktek shalat dan penyelenggaraan jenazah kepada siswa pada saat awal liburan.

\section{Evaluasi dalam Implementasi Pendidikan Agama Islam Berbasis Masyarakat}

Evaluasi dalam implementasi pendidikan agama Islam berbasis masyarakat di SMP Negeri 2 Candiroto berupa laporan yang disampaikan secara lesan dalam rapat dengan masyarakat maupun rapat pleno tahun ajaran baru oleh kepala sekolah. Sedangkan dalam evaluasi pembelajaran Pendidikan Agama Islam terutama dalam Baca Tulis Al Quran (BTA) dan praktek shalat dilakukan guru menjelang kenaikan kelas yang hasilnya disampaikan tertulis dalam bentuk rapot. Dan disampaikan kepada bapak ibu wali murid pada saat pengambilan rapot. Dari evaluasi hasil tes menunjukan kebanyakan dari siswa putra banyak belum lancar membaca, menulis al Quran dan praktek sholat di bandingkan siswa putri

Demikian juga halnya dalam evaluasi Implementasi Pendidikan Agama Islam berbasis masyarakat di SMP Muhammadiyah 5 Kandangan secara langsung disampaikan melalui rapat komite sekolah, maupun secara tidak langsung melalui pengurus maupun melalui yayasan, dan mengikut sertakan siswa dalam kegiatan masyarakat kegiatan di masyarkat sebagai pembaca kitab suci Al Quran, kegiatan shalat dhuhur dan shalat jumat bersamasama masyarakat di masjid dilingkungan sekolah seperti adzan dan shalat berjamaah sebagai bentuk pembiasaan akhlak siswa.

Implementasi pendidikan berbasis masyarakat bahwa masyarakatlah yang melakukan evaluasi dalam pelaksanaan pendidikan. Realitas yang terjadi dilapangan evaluasi pelaksanaan pendidikan dilakukan oleh pihak sekolah yang disampaikan melalui rapat komite maupun rapat pleno pada tahun ajaran baru. Ataupun secara tidak langsung dengan mengikutsertakan siswa dalam setiap kegiatan masyarakat.

\section{Dampak yang Muncul dalam Implementasi Pendidikan Agama Islam Berbasis Masyarakat}

Adapun dampak yang ditimbulkan dalam implementasi pendidikan agama Islam berbasis masyarakat

1) Dampak bagi siswa: semakin paham dalam memahami Al Quran, shalat dan semakin religious. disisi hal ini merupakan beban tambahan siswa dalam belajar karena tidak hanya disekolah saja.
2) Dampak bagi sekolah: semakin terbantu dalam kegiatan pembelajaran pendidikan agama Islam, terjalin kedekatan masyarakat dengan sekolah, disisi lain juga semakin membengkaknya anggaran pendidikan karena untuk menunjang kegiatan yang melibatkan masyarakat.

3) Dampak bagi masyarakat: kehidupan masyarakat menjadi lebih religius (terutama dalam beribadah), kegiatan perayaan keagamaan (Islam) semakin terbantu dengan kontribusi pihak sekolah

\section{Faktor Pendukung dan Penghambat dalam Implementasi Pendidikan Agama Islam Berbasis Masyarakat}

Faktor-faktor yang menjadi pendukung dalam implementasi pendidikan berbasis masyarakat yaitu

1) Adanya kesadaran akan pentingnya pendidikan yang semakin meningkat,

2) Banyaknya tokoh masyarakat berlatar belakang pondok pesantren,

3) Kultur gotong-royong yang masih kuat mengakar dimasyarakat desa sehingga memudahkan sekolah ketika mengadakan kegiatan yang melibatkan masyarakat dan

4) Bantuan dari tokoh masyarakat maupun unsur ranting muhammadiyah dalam pelaksanaan pendidikan agama Islam dengan memberikan rekomendasi siswa dalam tahfid quran maupun kegiatan lainnya.

Sedangkan faktor yang mejadi penghambat

1) Sumber Daya Manusia (SDM) intelektual masih minim,

2) Ketersediaan dana untuk kegiatan pendidikan berbasis masyarakat dari pihak sekolah selama ini masih tergantung dari dana BOS yang bersumber dari pemerintah,

3) Keuangan sangat tergantung dari hasil panen,

4) Komunikasi antara pihak sekolah dengan masyarakat yang kurang lancar sehingga memerlukan pendekatan lebih intensif. 


\section{PENUTUP}

Berdasarkan paparan data dan analisis Implementasi pendidikan agama Islam berbasis masyarakat di SMP Negeri 2 Candiroto dan SMP Muhammadiyah 5 Kandangan kabupaten Temanggung Tahun Pelajaran 2016/2017,

1) Implementasi pendidikan agama Islam berbasis masyarakat

a. Perencanaan, pelaksanaan, maupun evaluasi pendidikan masih di dominasi peran guru;

b. Partisipasi masyarakat dalam pendidikan agama Islam setingkat SMP masih memfokuskan pada penguasaan baca, tulis, hafalan Al Quran (Al- Quran hadits), praktek shalat shalat wajib maupun sunnah (Fiqh) serta pembiasaan membaca, menulis Al Quran dan Shalat berjamaah (Akhlak).

2) Dampak yang muncul dalam implementasi pendidikan agama Islam berbasis masyarakat di SMP Negeri 2 Candiroto dan SMP Muhammadiyah 5 Kandangan

a. Semakin meningkatkan pemahaman siswa terhadap Al Quran dan kemampuan shalat sehingga mendorong kehidupan masyarakat lebih religius; dan

b. Terjalin "simbiosis mutualisme" yang baik antara sekolah dengan masyarakat serta semakin membengkaknya anggaran pendidikan.

3) Faktor pendukung implementasi pendidikan agama islam berbasis masyarakat
a. Adanya kesadaran akan pentingnya pendidikan yang semakin meningkat,
b. Banyaknya tokoh masyarakat dan tokoh agama berlatar belakang pondok pesantren, mengakar dimasyarakat desa sehingga memudahkan sekolah ketika mengadakan kegiatan yang melibatkan masyarakat dan
c. Kultur gotong-royong yang masih kuat
d. Bantuan dari organisasi masyarakat/ yayasan.

Sedangkan faktor penghambat implementasi pendidikan Agama Islam berbasis masyarakat antara lain

e. Sumber Daya Manusia (SDM) intelektual masih minim,

f. Ketersediaan dana untuk kegiatan pendidikan berbasis masyarakat dari pihak sekolah selama ini masih tergantung dari dana BOS yang bersumber dari pemerintah.

\section{DAFTAR PUSTAKA}

Arifin, Anwar. 2003. Memahami Paradigma Baru Pendidikan Nasional dalam Undang-Undang Sisdiknas. Jakarta: Departemen Agama Republik Indonesia.

Ali, Mohamad.1999. Penelitian Kependidikan, Prosedur dan Strategi. Bandung: Angkasa.

Azra, Azyumardi. 2000. Pendidikan Islam;Tradisi dan Modernisasi menuju Milenium Baru, Jakarta: Logos Wacana Ilmu

Azwar, Saifuddin. 2009. Metode Penelitian, Yogyakarta : Pustaka Pelajar

Hashim, Che Noraini, dan Hasan Langgulung, 2008, Islamic Religious Curriculum in Muslim Countries: The Experiences of Indonesia and Malaysia, Bulletin of Education \& Research, Vol. 30, No. 1, pp. 1-19, hlm. 7

Hamilton E. Cunningham P. (1989). Communitybased adult education. In MerriamS. CunninghamP. (Eds.), Handbook of adult and continuing education (pp. 439-450). San Francisco, CA: Jossey-Bass.

Jalal, Fasli dan Supriadi, Dedi. 2001. Reformasi Pendidikan dalam Konteks Otonomi Daerah, Yogyakarta: Adicita Karya Nusa

Kaelan. 2012. Metodologi Penelitian Kualitatif Interdisipliner bidang sosial, budaya, filsafat, seni, agama dan humaniora. Yogyakarta; Paradigma

Khobir, Abdul, 2009, Pendidikan Agama Islam di Era Globalisasi, dalam jurnal Forum Tarbiyah, vol. $7 \mathrm{hlm} .3-4$

Molleong, Lexy J. 2005. Metodologi Penelitian Kual itat $i$. Terj. B and ung: Rem a ja Rosdakarya.M.B. Miles, dan A.M. Huberman. 2002. Analisa Data Kualitatif. terj. Tjetjep Rohendi Rohidi, Jakarta : Universitas Indonesia Press.

Muhaimin, dkk. 2009. Pengembangan Model Kurikulum Tingkat Satuan Pendidikan (KTSP) pada Sekolah dan Madrasah. Jakarta: Raja Grafindo Persada.

Muthoifin, 2015, Jurnal Studi Islam dan Sosial: 
PROFETIKA, Jurnal Studi Islam, Vol. 19, No.1 Juni 2018: 6 - 12

Sistem Pendidikan Nasional dan Pendidikan Islam, Studi Kritis Pemikiran Ki Hadjar Dewantara Perspektif Islam. Vol 2, No 1 Wahana Akademika page. 61-75 Kopertais Wilayah X Jawa Tengah

Noor, Wahyudi, 2014, Jurnal Qathruna, Rekontruksi Pendidikan Agama Islam, (Banten: penerbit, 2014). Vol. 1., hlm. 43

Shobron, Sudarno dkk. 2016. Pedoman Penulisan Tesis MpdI, MPI, MHI, Surakarta; Sekolah PascaSarjana UMS.

Suharto, Toto, 2012 Pendidikan Berbasis Masyarakat: Relasi Negara dan Masyarakat dalam Pendidikan, Yogyakarta: LkiS.

Tilaar, H.A.R. 1999. Pendidikan,Kebudayaan dan Masyarakat Madani Indonesia, Strategi Reformasi Pendidikan Nasional. Bandung: Remaja Rosdakarya.

Umaedi. 2001. Managemen Peningkatan Mutu Berbasis Sekolah. Jakarta: Departemen Pendidikan Nasional Direktorat Jendral Pendidikan Dasar dan Menengah Direktorat Sekolah Lanjutan Tingkat Pertama

Zubaedi. 2006. Pendidikan Berbasis Masyarakat Upaya Menawarkan Sosulsi terhadap Berbagai Problem Sosial. Yogyakarta: Pustaka Pelajar 